\title{
ABSTRACTS FROM THE ORIGINAL ARTICLES.
}

\section{VERGLEICH DER VERSCHIEDENEN PFLANZENZELLSTOFFE ALS ROHMATERIALIEN FÜR ZELLULOID.}

\section{Von Hirotaro Nishida, Kogakuhakushi.}

Durch diesen experimentalen Vergleich bestätigte Verf., dass für gewisse Arten des Zelluloids die billigeren Zellstoffe mit Erfolg verwendbar sind und dass selbst die Zellstoffe des Bambus sowie die der für echt japanisches Papier angewandten Bastfasern und die des Reisstrohs sowie des Holzes als ein Teil des Rohmaterials gebraucht werden können. Die Beschreibung der Vorbehandlungen der für diese Versuche gebrauchten Zellstoffe und auch die Kupfer= und Sïurezahlen nach Schwalbe und Viewig, der Oxyzellulosegehalt nach der erst vom Verf. empfolenen Methode mit Titanchlorid, der Aschengehalt und die besten Nitrierungsbedingungen derselben sind ausführlich dargelegt.

Die beste Nitriersüure hat folgende Bestandteile: $\mathrm{H}_{2} \mathrm{SO}_{4} 64.0-65.5 \%$, $\mathrm{HNO}_{3}$ 15.0-16.5\%, $\mathrm{HNO}_{2}, 0.8-1.0 \%, \mathrm{H}_{2} \mathrm{O}$ 1 $8.0-19.0 \%$. Die Gegenwart von salpetriger Säure ist nicht wünschenswert, aber unvermeidlich, insofern die Handelssäure gebraucht wird. Das optimale Verhältnis zwischen der Zeitdauer und der Temperatur der Nitrierung kann man in die folgende sehr einfache Gleichung formieren :

$$
\mathrm{T} \times \mathrm{Z}=\mathrm{K},
$$

wo $\mathrm{T}$ Temperatur, $\mathrm{Z}$ Zeitdauer in Minuten und $\mathrm{K}$ eine für gegebene Zellstoffe eigentliche Konstanz ist. Die letztere hat folgende Werte: 1500 für Baumwollezellstoff, 2100 für Flachs= und Bastfasern, 2400 für $\mathrm{Holz}=$ und Strohzellstoff, 2700 für geschliffenen Holzzellstoff und für andere 
schwierig zu nitrierende Zellstoffe, sofern das Gewicht pro Quadratmeter des Papiers 40 gr. nicht überschreitet; in dem Falle, wo sein Gewicht grösser als 40 gr. ist, jede Zahl mit $0^{\circ} 9 \sqrt{\frac{D}{40}}$ bzw. $0 . S_{5} \sqrt{\frac{D}{40}}$ multipliziert werden muss, je nach dem Gewicht der einheitlichen Fläche des Papiers, was in den Formeln mit D bezeichnet ist, 40 bis $100 \mathrm{gr}$. bzw. IOO bis $200 \mathrm{gr}$.

Verf. ordnete die Eigenschaften der so hergestellten Nitrozellulose und die des daraus gewonnenen Zelluloids in eine Tabelle an; Der lösliche Teil der Nitrozellulose wurde bestimmt und in Prozenten dargestellt, indem 2 gr. Nitrozellulose in $100 \mathrm{ccm}$ alkoholischer 30\% iger Kampferlösung gelöst und von einem Teil der überstehenden klaren Lösung die gelöste Menge derselben bestimmt wurde; die Viskosität ;wurde auf diese Lösung mittelst des Engler'schen Apparats im Vergleich mit destillierten Wasser bestimmt ; die Stabilität des Zelluloids nach der modifizierten Will'schen Methode und:Zugfestigkeit sowie Biegungsmoment des Zelluloids mittelst des für diese Zwecke vom Verf. neu angestellten hydraulischen Apparats wurde mit dem aus entfetteter Baumwolle hergestellten Zelluloid verglichen.

Zufolge dieser Resultate teilte Verf. die verschiedenen Zellstoffe in die folgenden sechs Klassen ein, die Qualität ist der Reihenfolge nach angegeben, die erste ist die beste.

I. Nicht gebleichtes, merzerisiertes Baumwollgarn.

Seidenpapier aus weissen Lumpen und aus Fischnctzen.

2. Gebleichtes, merzerisiertes Baumwollgarn.

Seidenpapier aus farbigen Lumpen und aus Flachslumpen.

3. Papier aus anderen Bastfasern.

Gereinigtes, gebleichtes Abfallgarn aus Baumwollspinnereien.

4. Möglichst gereinigter, nass geschlagener Baumwollzellstoff.

5. Chemischer Holzzellstoff und möglichst gereinigter Strohzellstoff.

6. Mit kleiner Menge Baumwolle versetzter, mechanischer Holzzellstoff.

\section{ÜBER DAS CHRYSALISOEL.}

\section{Von Mitsumaru Tsujimoto, Kogakuhakushi.}

Neuerlich wurden zwei neue Arten dieses Oeles auf unsern Markt 
gebracht; das erste wird aus getrockneten Chrysalis durch Extraktion mit Petrolaether gewonnen, während das zweite aus nicht getrockneten und zwar bald nach Entziehen der rohen Seide im frischen Zustande durch Pressen gewonnen wird, obgleich früher allgemein getrocknete gepresst wurden.

Verf. untersuchte die Eigenschaften und die Reinigungsmethoden dieser beiden Oele mit dem Resultat, das das erste mit Bleicherde allein und das zweite mit Schwefelsäure und Bleicherde nicht schwierig zu reinigen ist. 